\title{
EL CUERPO COMO FUNDAMENTO DE LA SOCLALIDAD en José Ortega y GasseT
}

\author{
Miguel Vicente-Pedraz ${ }^{l}$ \\ María Paz Brozas-Polo ${ }^{2}$
}

RESUMEN: Este artículo constituye un acercamiento a la noción de cuerpo en el pensador español José Ortega y Gasset (1883-1955), sobre todo, en lo que aquel tiene de motivo en sus indagaciones fenomenológicas sobre la socialidad. A partir del análisis de los textos más representativos de la sociología y la antropología orteguianas, se pone de relieve que el cuerpo no es un elemento aislado ni esporádico sino, más bien, un elemento mediador de lo más representativo de su pensamiento.

Palabras Clave: Ortega y Gasset. Cuerpo. Expresión. Sociedad. Socialidad.

\section{INTRODUCCIÓN}

Acercarse a cualquiera de los ángulos del pensamiento de Ortega y Gasset (1883-1955) resulta una tarea siempre comprometida dada la amplitud temática y la profundidad de su obra. Lo es, particularmente, teniendo en cuenta el carácter heterogéneo y hasta disperso de su discurso, a menudo inacabado o fragmentario, a pesar de la unidad interna que le confieren las tradiciones filosóficas que lo informan: desde el neokantismo y la fenomenología del periodo de juventud hasta el vitalismo y el historicismo en el ápice de su plenitud creadora; todo ello sin olvidar los elementos que subyacen a su formulación metafísica, los cuales anticipan, según Malisev y Herrera (2010,

\footnotetext{
${ }^{1}$ Profesor Titular en la Universidad de León, León - Espańa. E-mail: mvicp@unileon.es Doctor-investigador en el ámbito de los usos y representaciones sociales del cuerpo.

2 Profesora Titular en Universidad de León, León - España. E-mail: mpbrop@unileon.es Doctora-investigadora en el ámbito de las estéticas corporales en el Siglo XX.
}

http://dx.doi.org/10.1590/0101-3173.2018.v41n3.09.p169 
p. 218), algunos de los motivos existencialistas de Heidegger -o, al menos los recuerda (CARVALHO, 2015, p. 179) - y que el propio Ortega le disputaría vivamente tal como detalló su discípulo José Gaos a principios de los años sesenta (GAOS, 1961). A la vez, y como elemento condicionante, cabe anotar el carácter transversal que adquieren sus indagaciones, las cuales, pese a ser indudablemente filosóficas, sirven de vehículo a preocupaciones temáticas de carácter antropológico, histórico, sociológico y psicológico (la naturaleza, la vida, la cultura, la sociedad, el Estado, el cuerpo, los gestos, el yo, el alma, la comunicación, el deporte, la tauromaquia, el arte, la educación, etc.) en una época en la que las ciencias sociales están en plena ebullición, definiéndose algunas de ellas, y todas a la búsqueda de sus fundamentos y de un paradigma.

La cuestión del cuerpo, sin ser un tema central ni de primer orden en el conjunto de sus preocupaciones, presenta algunos episodios realmente notables y definitorios de su pensamiento; particularmente, de lo que podríamos denominar su pensamiento psicológico y sociológico. La tesis que aquí defendemos es que, al menos en estos campos, sus indagaciones fenomenológicas en torno al cuerpo no son un elemento aislado ni esporádico sino, más bien, un elemento mediador de su pensamiento. Aunque aparece ya en sus escritos de juventud, ligado al concepto de naturaleza como cosa pensada, de acuerdo con el idealismo neokantiano en el que profesó durante algún tiempo, sus más interesantes aportaciones tienen lugar a raíz de la adopción del perspectivismo, hacia 1914 cuando publica Meditaciones del Quijote y, sobre todo, a partir del giro vitalista, en torno a 1924. Es justamente desde mediados de los años veinte -con la publicación de los artículos que integrarían los tomos centrales de El espectador, Qué es filosofía, Ideas y creencias etc.-, y hasta su muerte -con la aparición póstuma de El hombre y la gente-, donde se halla lo más granado y singular de su sistema, el raciovitalismo; un marco desde el que interpreta, reelabora y desarrolla -también da por superado, como en el caso del neokantismo, e intenta superar, como en el caso de la fenomenología (CEREZO, 1984; SAN MARTÍN, 2012)- muchas de las formulaciones de las que se impregnó en su periodo de formación en Alemania, entre los años 1905 y 1907, sobre todo en Berlín, Leipzig y Marburgo.

Del periodo perspectivista, caracterizado por la oposición al idealismo puro y al realismo, ya es posible extraer alguna concepción que sería determinante para la comprensión de la socialidad del cuerpo en la medida en que entiende al individuo como una pantalla que selecciona las impresiones de lo dado: no como cosas abstractas, sino como realidades instaladas en un haz 
de relaciones contingentes que, el sujeto, corporalmente localizado en el aquí y ahora, hace transcender en la razón y la cultura: "Porque el mundo -decía en Meditaciones del Quijote- no es ni materia ni alma, sino una perspectiva" (ORTEGA Y GASSET, 1976, p. 29), o dicho de otro modo, ahora en El tema de nuestro tiempo, el sujeto es un inmediato, una circunstancia, una vida individual que, merced a su localización -corporalidad situada en el mundo-, accede a la verdad: "Cada vida es un punto de vista sobre el universo. En rigor, lo que ella ve no lo puede ver otra. Cada individuo [...] es un órgano insustituible para la conquista de la verdad. [...]. El error inveterado consistía en suponer que la realidad tenía por sí misma, e independientemente del punto de vista que sobre ella se tomara, una fisonomía propia." (ORTEGA Y GASSET, 1980, p. 86-87).

La interpretación de los valores culturales, entendidos como funciones vitales -según la tesis "yo soy yo y mi circunstancia, y si no la salvo a ella no la salvo yo. Benefac loco illi quo natus es, leemos en la Biblia" (ORTEGA Y GASSET, 1976, p. 30), formulada en 1914 en Meditaciones del Quijote-, conduciría a Ortega a las posiciones filosóficas ulteriores según las cuales el concepto -elemento básico de la razón- se mostraría como el auténtico órgano del conocimiento; órgano que permite comprender la noción de razón vital, forma orteguiana de la razón histórica. Según esta, todo conocimiento, también el conocimiento racional, está arraigado en la vida, es decir, es vital o viviente: "La razón no puede, no tiene que aspirar a sustituir la vida [...] como si la razón no fuera una función vital y espontánea del mismo linaje que el ver o el palpar" (ORTEGA Y GASSET, 1976, p. 80). El hombre -sentencia en ¿Qué es filosofía?-, más que un ser dotado de razón y, sobre todo, antes que ello, es un ser viviente; un ser que no tolera preparación ni ensayo previo porque "la vida en su totalidad y en cada uno de sus instantes tiene algo de pistoletazo que nos es disparada a quemarropa" (ORTEGA Y GASSET, 1981a, p. 192); su realidad radical consiste en estar condenado a vivir por lo que se ve obligado a inventar y usar la razón, para no perderse en el universo. La vida, por lo tanto, es la realidad radical dentro de la cual se encuentran las demás realidades pero, propiamente, la vida no es nada. Ha de hacerse a sí misma tratando con las cosas del mundo en la existencia concreta de cada cual -la circunstancia-. A este respecto, siendo la vida, en primera instancia, un problema o un quehacer particular, un drama y un naufragio del que el hombre se salva agarrándose a la tabla de la cultura, no puede entenderse como una realidad biológica sino biográfica, narrativa: el ser no es una realidad sino una interpretación, una de tantas sobre lo que hay. 
Bajo esta consideración, frente a lo técnicamente natural considerado como mecánico, predeterminado, sometido a una ley fija-, y frente a la función, que fuerza a hacer algo determinado, la vida se define y se realiza en el quehacer; es algo que nos obliga a decidir antes de hacer. Eso sí, nos obliga a decidir contando con -o estando en- una creencia que, al fin y al cabo, es para Ortega el sostén de la razón vital e histórica (narrativa y biográfica) cuya aparición tiene lugar ante el fracaso de la razón física en su incapacidad de decir nada claro sobre el hombre (ORTEGA Y GASSET, $1981 b$, p. 25-26). En última instancia, como ha señalado Sanmartín (1998, p. 82), Ortega remite a la historia para ensayar la comprensión de los fenómenos sociales y culturales, lejos del utilitarismo funcionalista de inspiración biológica: "Porque el hombre no tiene naturaleza. El hombre no es su cuerpo [...] ni es su alma [...] sino un drama [...]. En suma, el hombre no tiene naturaleza, sino que tiene... historia." (ORTEGA Y GASSET, 1981b, p. 48).

\section{LA ENCRUCIJADA DUALISTA}

Con tales presupuestos, el cuerpo aparece como cuestión nuclear en numerosos ensayos -algunos tan representativos de su pensamiento como Vitalidad, alma, espíritu y La percepción del prójimo de 1924 o, también, en Sobre la expresión fenómeno cósmico de 1925. Ciertamente, tras estos escritos hay un largo periodo en el que el cuerpo parece quedar en un segundo plano, como latente, tal como sucede, por ejemplo, en su obra más difundida La rebelión de las masas de 1930. Sin embargo, prueba de que mantuvo un vivo el interés por el cuerpo hasta su muerte, es la publicación póstuma de El hombre y la gente; una obra cuya preparación había anunciado más de veinte años antes de que viera la luz en 1957 $\mathrm{y}$, en donde, entre otros aspectos, expone las líneas fundamentales de su pensamiento ontológico y sociológico a partir de la aprehensión del propio cuerpo y del cuerpo del «otro».

En todo caso, el cuerpo no aparece en Ortega como algo que haya que analizar como tal sino más bien como el elemento con relación al cual deben ser abordados algunos problemas; es decir, no tanto porque estos encuentren solución en el cuerpo sino porque este está necesariamente presente. Conforma una especie de marco inevitable en cuyo interior los demás asuntos tienen su razón de ser; particularmente, los asuntos 
antropológicos y los psicológicos, pero también los que involucran la expresión y la comunicación y, desde luego, los que tienen que ver con el dominio de las cosas y de la naturaleza (BASSANI; VAZ, 2014, p. 219220) tal como se pone de relieve, sobre todo, en Meditación de la técnica (ORTEGA Y GASSET, 1982).

Inicialmente, como preámbulo que debe ser matizado, el concepto de cuerpo en Ortega contiene los elementos básicos de la histórica contradicción en la que ha estado sumida la cultura cristiana occidental desde sus inicios. El cuerpo es carne, y como tal, peligro, asechanza, pero a la vez es condición imprescindible del modo de ser hombre; es el requisito de la acción primigenia humana: vivir; es decir, la acción que uno lleva a cabo consigo mismo en soledad radical porque "todo vivir es vivirse, sentirse vivir." (ORTEGA Y GASSET, 1981a, p. 188). Pero, a la vez, el cuerpo es requisito de las acciones, secundarias aunque inevitables, de la convivencia: las acciones sociales. Con esa perspectiva, ya en Vitalidad, alma, espiritu planteaba la necesidad de formular una antropología filosófica orientada a desentrańar la intimidad humana a partir de, o al menos contando con, el cuerpo -particularmente, el intracuerpo- desde la superación del dualismo: "Necesitamos no perder ningún ingrediente: alma y cuerpo [...]. El tiempo avanza con letras en las banderas: "Lo uno y lo otro». Integración. Síntesis. No amputaciones." (ORTEGA Y GASSET, 1987, p. 455). A partir de ahí, prácticamente todos los escritos del periodo raciovitalista tienen presente el hecho de la corporalidad, ya fuera como fundamento de la razón vital o como estructura perceptiva y expresiva que posibilita la experiencia del vivir -la vivencia- en cada ámbito concreto, es decir, en su circunstancia. A este respecto, como ha señalado Orringer (1999, p. 9), Ortega y Gasset vaticinó en 1924, probablemente influido por Scheller, el advenimiento de una filosofía del cuerpo: "Fuera oportuno sermonear un poco a los que sermonean contra el cuerpo [...] es un tema de insuperable actualidad porque el hombre europeo se dirige recto a una gigante reivindicación del cuerpo, a una resurrección de la carne." (ORTEGA Y GASSET, 1987, p. 453)

Todo ello, no evita que en ocasiones Ortega se muestre reticente con respecto al cuerpo o, al menos, con la dimensión social que eventualmente cobraba la cultura o el cultivo del cuerpo, hasta declarar que el cuerpo es un tema aburrido: 
Yo creo que la reivindicación del cuerpo es una de las normas mejores de nuestro tiempo [...]. No se trata ya de culto y cultivo del cuerpo, sino que este se revuelve contra el espíritu y el muy imbécil aspira a modificarlo. Por fortuna [...] se empieza a sentir asco de tanto cuerpo. Asco y aburrimiento. Porque el tema del cuerpo es, ante todo, un tema aburrido: tiene escaso repertorio y apenas se exagera la atención a él, repugna. (ORTEGA Y GASSET, 1966, p. 209).

\section{EL CUERPO COMO EXTERIORIZACIÓN DE LA INTIMIDAD}

Las ideas básicas en torno a la interpretación de lo corporal, exégesis del pensamiento dualista de la tradición cristiana, aunque repartidas a lo largo de toda la obra, aparecen bien condensadas en los diferentes tomos donde básicamente plantea que el cuerpo del hombre no es, propiamente dicho, el hombre. El cuerpo se presenta como la exteriorización de algo no espacial y absolutamente interno -alma, conciencia, espíritu, psique, yo, persona- que por sí mismo no puede hacerse externo. Se trata, en esencia, de la intimidad; lo que denominamos vida y que, a diferencia de toda otra realidad, es constitutiva e irremediablemente una realidad oculta de tal manera que "el hombre exterior está habitado por un hombre interior. Tras el cuerpo está emboscada el alma." (ORTEGA Y GASSET, 1966, p. 29). Y esta ocultación es precisamente el fundamento de la capacidad expresiva puesto que "para que haya expresión es menester que existan dos cosas: una, patente, que vemos; otra, latente, que no vemos de manera inmediata, sino que se nos aparece en aquella." (ORTEGA Y GASSET, 1966, p. 29).

Pero Ortega no se queda en la cruda división dualista cuerpo-alma. Dicha división es sólo el basamento cultural en el que apoya la exploración fenomenológica, la cual alcanza algunas de sus más genuinas manifestaciones tanto en Sobre la expresión fenómeno cósmico como en Vitalidad, alma, espiritu. En la primera, integrada en el volumen séptimo de El espectador, diría:

Es una falsa descripción de los fenómenos, del hecho según él se ofrece, decir que primero vemos del hombre solo un cuerpo parejo al mineral y que luego, en virtud de ciertas reflexiones, insuflamos en él mágicamente un alma. La verdad es lo contrario [...]. La carne se nos presenta de golpe, y a la vez, un cuerpo y un alma en indisoluble unidad. [...] Todo fenómeno expresivo, implica, pues, una transposición, es decir, una metáfora esencial. El gesto, la forma de nuestro cuerpo es la pantomima de nuestra alma. (ORTEGA Y GASSET, 1966, p. 30-31). 
Y es así porque el cuerpo del hombre no es un simple cuerpo como el mineral que, por ser todo exterioridad, permite que nuestra percepción descanse y termine en su aspecto. El cuerpo del hombre lo vemos como carne; es decir, como un medio transparente que desnuda el alma, la intimidad que lo habita y, en ese sentido, "es lo que no es y, «además», significa lo que no es: un alma. La carne del hombre manifiesta algo latente, tiene significación, expresa un sentido [...]. Es la expresión como fenómeno cósmico.” (ORTEGA Y GASSET, 1966, p. 32).

Aquí, a partir de la idea de cuerpo como forma espacial cargada de intimidad, Ortega configura toda una teoría de la expresión que despliega con un abanico de términos tales como encarnación, transposición, emanación, señalización, significación o espacialización, sobre los que, además, propone una taxonomía de los elementos del cuerpo como diferentes campos de manifestación: el gesto, en tanto expresión genérica de emoción; las variaciones, que serían la expresión particular de la intimidad o las modulaciones que colorean la línea geométrica que envuelve el gesto; la mirada, la forma de expresión más incorpórea, el alma hecha fluido; la figura, ingrediente expresivo que, según Ortega, no sólo va disuelto en el movimiento sino también en la forma orgánica; y, finalmente, el traje, que -dice- fue inventado para subrayar el cuerpo, no sólo lo cubre sino que lo descubre porque simboliza los estados interiores. (ORTEGA Y GASSET, 1966, p. 39-46).

Como dice Koprinarov (2012, p. 529), el cuerpo es para Ortega el cimiento de la intersubjetividad, precisamente porque además de ser sí mismo, es símbolo de algo más; es escenificación espontánea e inconsciente de la intimidad del hombre lo que se hace especialmente manifiesto en la gesticulación mediante la cual, junto con la fisonomía -y antes que con las acciones-, el cuerpo habla (ORTEGA Y GASSET, 1966, p. 41). Y esto hasta tal punto que, para Ortega, como dirá más años más tarde en El hombre y la gente: "La producción de sonidos articulados es sólo un lado del hablar. El otro lado es la gesticulación total del cuerpo humano mientras se expresa [...]: hablar es gesticular.” (ORTEGA Y GASSET, 1981c, p. 254).

La exploración sobre el cuerpo, ya no tanto como entidad expresiva particular sino como genuina entidad antropológica que alcanza a todas las esferas de la realidad humana, ya aparecía en el segundo ensayo mencionado Vitalidad, alma, espiritu integrado en el quinto volumen de El espectador en el que emplea por primera vez el término intracuerpo, acuñado probablemente a partir del concepto de cuerpo vivido (Leib) de Scheller (ORRINGER, 
1999, p. 11), aunque haya quienes, como Laín Entralgo (1989, p. 116), hayan atribuido a Ortega la audacia de ocuparse por vez primera, de manera temática en la filosofía, del sentimiento del cuerpo propio. En todo caso, se trata de un concepto muy próximo también a Husserl y a Bergson (MERMALL, 1988) no exento de la estimación por el cuerpo como materia filosófica que había recibido directamente de la lectura de Nietzsche (OSÉS, 1989 , p. 21 y ss).

La noción de intracuerpo surge, según Ortega, de la (exploración) tectónica de la intimidad humana en cuya estructura cabe distinguir, al menos, tres regiones de la personalidad: la primera, en un hipotético trayecto de fuera adentro, es la vitalidad; una especie de alma carnal donde se funden -dice- lo somático y lo psíquico, lo corporal y lo espiritual. Es, asimismo, el lugar donde se funden las imágenes externa e interna que cada cual tiene de sí -porque no hay que olvidar que el hombre tiene esta doble perspectiva de sí- y, siendo como es cimiento y raíz de nuestra persona, determina el carácter. Pues bien, el intracuerpo es esa imagen, inédita en el universo excepto en el hombre, que en esta primera región de la intimidad se forma a partir de "las sensaciones de movimiento o táctiles de las vísceras y los músculos, por la impresión de las dilataciones y contracciones de los vasos [...] y viene a ser como el marco dentro del cual todo se nos aparece [...]. Es el personaje invariable que interviene en todas las escenas de nuestra vida." (ORTEGA Y GASSET, 1987, p. 456-457).

Tras el fondo de la vitalidad, en el centro de la persona, y menos corpóreo que esta, se halla el espiritu; es estrictamente lo que puede llamarse yo y lo forman el conjunto de actos íntimos de los que cada cual se siente autor y protagonista; es con lo que se quiere y con lo que se piensa y esta es justamente su función porque ni con el cuerpo ni con el alma -dice Ortega- se piensa. Finalmente, el alma envuelve y alimenta al yo, al espiritu; es el lugar de donde brotan los sentimientos y las emociones que, frente al carácter intemporal o instantáneo de los pensamientos, son durativos.

En última instancia, es a través de la noción de intracuerpo que Ortega encuentra una fructífera vía de escape del solipsismo al que la idea de soledad como realidad radical podía conducirle. Porque, en efecto, el intracuerpo, en tanto que instancia intrínseca de la vitalidad o alma corporal, se encuentra en el meollo de la personalidad en parte opaca y en parte transparente y, por tal condición, fundamento de la expresión, cuando menos, por la vía del contagio; porque: "La vida es precisamente la realidad única, entre todas las 
del cosmos, que se contagia. Hasta el punto que cabría, por uno de sus haces, definir la vida como aquello que es capaz de contaminar y contaminarse." (ORTEGA Y GASSET, 1987, p. 459).

\section{EL CUERPO ENTRE LA SOLEDAD Y LA SOCIEDAD}

Dada la soledad radical en que consiste la vida humana, que es siempre la de cada cual, es esta facultad de contaminación vital lo que en última instancia fundamenta y posibilita la sociedad o, más propiamente, lo social, lo colectivo que, en definitiva está constituido por todos aquellos elementos que la historia ha ido desalmando, consolidando en usos y creencias, y que ya no son de nadie porque son de la gente. Es decir, es lo humano sin alma, sin espíritu, lo humano sin el hombre, deshumanizado.

Bajo esta perspectiva, resulta especialmente interesante la consideración orteguiana de las relaciones interindividuales como vínculos humanos, a medio camino entre la vida personal y la vida social propiamente dicha. Si bien lo social consiste en acciones o comportamientos humanos, la vida humana es siempre la de cada cual, es la vida personal forzada a existir en una circunstancia. De esta forma, para Ortega sólo es humano en sentido estricto y primario lo que cada uno hace por sí mismo y en vista de sus propios fines. Es decir, "sólo es propiamente humano en mí lo que pienso, quiero, siento y ejecuto con mi cuerpo siendo yo el sujeto creador de ello, o lo que a mí mismo, como tal mí mismo, le pasa" (ORTEGA Y GASSET, 1981c, p. 13). De ello deduce que la vida humana es, en esencia, soledad. Lo social surge como un resultado (no primario) de la convivencia o trato entre dos vidas individuales; pero dicha convivencia no es, en sí misma, constitutiva del hecho social porque siempre está arraigada en un sujeto creador y responsable de sus acciones. El hecho social lo constituyen las acciones o intelecciones específicamente humanas que aun teniendo su origen en la convivencia y estando impuestas por su contorno no parten del sujeto individual sino de la gente, de la colectividad, de la sociedad, de lo que suele llamarse uso y que no es sino "lo que pensamos o decimos porque se piensa o se dice, lo que hacemos porque se hace" (ORTEGA Y GASSET, 1981c, p. 15). Desde el fondo de la realidad radical que es, irremediablemente, nuestra vida emergemos -según señala Ortegaen un ansia, también radical, de compañía; como si quisiéramos encontrar a aquel cuya vida se pudiese fundir o interpenetrarse con la nuestra en el nunca 
bien cumplido "intento de canjear dos soledades" (ORTEGA Y GASSET, 1981c, p. 57) por obra de la (limitante) materialidad de nuestro cuerpo.

En efecto, aunque para Ortega existe cierta posibilidad de sentir las cosas exteriores dentro del cuerpo -posibilidad proporcionada por el sentido del tacto que permite sentir las cosas dentro de uno y no fuera como en la visión o la audición-, la materialidad corporal no deja de ser un obstáculo para la relaciones sociales y de convivencia las cuales suceden siempre mediante un choque corpóreo; un choque que, por otra parte, es constitutivo de la realidad y de la propia realidad solitaria del hombre: el contorno o mundo patente se compone sobre todo de presencias, de cosas que son cuerpos que chocan con la cosa más próxima al hombre, su cuerpo. Justamente lo que hace que todos los demás sean cuerpos y que el propio mundo -que nos oprime, comprime y reprime, según dice- lo sea. El hombre es, de esta manera, alguien que está en un cuerpo y sólo en ese sentido -subraya Ortega- es su cuerpo; un hecho simple pero irremediable que es lo que decide la estructura concreta de nuestro mundo y, con ello, nuestra vida y nuestro destino. El hombre se encuentra de por vida solitariamente recluso en su cuerpo-cuerpo tumba, cuerpo cárcel, sôma sêma pitagórico- en una dramática impenetrabilidad.

Pero, aunque la vida humana es en esencia soledad -de cuya experiencia íntima el intracuerpo es imagen-, el cuerpo externo coloca al hombre en relación con otros hombres. Esta relación, que es lo social, la convivencia, el hecho comunicativo, no es en esencia vida sino trato entre dos vidas individuales que, no obstante, coloca al hombre a través de los usos sociales en un determinado contorno del que no se puede desasir salvo mediante el ensimismamiento (HARO, 2010); es decir, mediante la momentánea renuncia a la alteración -estado natural del animal- o, lo que es lo mismo, volviendo la espalda a las cosas del mundo, resistiéndolas, para desprenderse de su animalidad (ORTEGA Y GASSET, 1981c, p. 27-30).

Pero, tanto una cosa como la otra, mantenerse en estado de alteración y ensimismarse, lo puede hacer el hombre por tener vitalidad, alma y espiritu $y$, además, por estar inexorablemente en un cuerpo. Y estar en un cuerpo trae consigo no sólo que todas las cosas y el mundo sean cuerpos sino también que todas las cosas, incluso las no corporales -si es que las hay, dice Ortega-, estén colocadas con relación a mí o a mi cuerpo; colocadas en una perspectiva, la mía, que se construye o me construye porque vivo infuso y recluso en $\mathrm{mi}$ cuerpo haciendo de mí un personaje espacial, localizado. La localización-que luego desarrollaría Marías (1983, p. 112-119) en el concepto de instalación 
corpórea- le supone al hombre el destierro de toda otra situación que la propia; le supone la imposible ubicuidad que, de manera tan fulminante señala el vocablo castellano aquí: este "por su acento tan vertical me clava como un clavo... aquí." (ORTEGA Y GASSET, 1981c, p. 81). A ese respecto, al tener que sernos el mundo, con todas las cosas dentro de él, desde aquí, se convierte automáticamente en una perspectiva impenetrable donde nuestros "aquis» se excluyen, por lo que nuestros mundos -el mío y el de los otros, apunta Ortega- no coinciden suficientemente: no sólo yo estoy fuera de cualquier otro hombre por causa de la impenetrabilidad física de mi cuerpo, sino que también mi mundo está fuera del suyo: "Somos mutuamente dos "fueras» y por eso somos radicalmente forasteros" (ORTEGA Y GASSET, 1981c, p. 82).

Pero, si la realidad radical del hombre es la soledad, si somos radicalmente forasteros, ¿cómo aparecen en el mundo vital de cada hombre los otros hombres?; ¡ंen qué modo se da la presencia de los otros?

La relación que se da entre los hombres -e incluso entre los hombres y los animales, a diferencia de lo que sucede entre aquel y la materia inerte o las plantas- es una relación que se puede denominar -seńala Ortega- de mutualidad o reciprocidad; es decir, una relación en la que otros hombres $\mathrm{y}$ animales me responden. Es este responderme lo que me alerta de que unos y otros existen no solo para mí, sino que también yo existo para ellos y, en consecuencia, co-existen conmigo, donde "el coexistir es un entrepeinar las existencias, un entre o interexistir dos seres, no simplemente "estar ahí» sin tener que ver el uno con el otro" (ORTEGA Y GASSET, 1981c, p. 94), lo cual es ya, de primeras, lo que denominamos trato social; algo que apunta a una realidad consistente en que el hombre se comporta frente a otros seres que, a su vez, se comportan con respecto a él; una realidad en la que dos actuantes se responden mutuamente, es decir, se co-rresponden.

Ahora bien, la co-rrespondencia con la que se manifiesta la relación entre el hombre y el animal queda reducida -según Ortega- a un repertorio muy exiguo de actos míos y de actos suyos de tal manera que para co-existir más con el animal lo que tiene que hacer el hombre es reducir su propia vida, elementalizarla hasta convertirse en casi otro animal.

¿Se puede, entonces, o no se puede reconocer como hecho social el trato o la co-existencia del hombre con el animal? La pregunta se la formula Ortega como forma de escudriñar lo que intuitivamente se podría considerar como una forma protosocial para, a partir de ella, entrever qué son y cómo 
suceden las verdaderas y palmarias relaciones sociales. Y en efecto, Ortega se responde a sí mismo que, si bien la relación que se establece entre animales y hombres es ya una co-rrespondencia, el carácter confuso, ambiguo y borroso que percibimos en el modo de ser del animal es una verdadera limitación de la co-existencia hasta el punto de que nunca sabemos bien como tratarlo, si humanamente, vegetalmente o incluso mineralmente y que, en consecuencia, no podamos saber si dicho trato es social. Para decidirlo se hace necesario aventurarse en el análisis de lo irrecusablemente social y, a partir de ahí, establecer la oportuna comparación.

Entonces, lo irrecusablemente social se da, por definición, cuando en el mundo vital, en mi mundo vital, aparecen "esas cosas que llamamos "hombres»", esos seres ante cuya presencia reflexiva sentimos cierta inquietud, una alerta suspicaz que no provocaba el trato con el resto de las cosas del horizonte porque, parafraseando a Nietzsche, no tenían opinión sobre nosotros. ¿Quién es el otro, el otro hombre?, ¿cómo se muestra ese peligro que nos azora, pero cuya presencia nos desliza hacia el trato social? El otro -dice Ortega- es aquel de quien, con presencia sensible, sólo tengo un cuerpo, un cuerpo que ostenta una peculiar forma, que se mueve, que se comporta externa o visiblemente. Pero lo sorprendente y extrańo -señala-, lo últimamente misterioso, es que siéndonos presente sólo una figura y unos movimientos corporales, vemos en ello o a través de ello algo por esencia invisible, algo que es pura intimidad: su pensar, su sentir, su querer. Operaciones, estas, que cada cual sólo puede conocer directamente las de sí mismo y que no pueden ser presencias para otros porque son no-externas y ni siquiera se pueden exteriorizar directamente porque, a diferencia del cuerpo que somos, no ocupan espacio ni tienen - dice-cualidades sensibles.

Pues bien, estas operaciones que son la intimidad o incorporeidad, este dentro, es donde se prepara la coexistencia que -según Ortega- casi llegaba a darse en el trato con el animal y se da verdaderamente entre los hombres porque "todo coexistir es un coexistir de dos intimidades." (ORTEGA Y GASSET, 1981c, p. 98). A este respecto, aunque la carne por su espacialidad imposibilita la penetrabilidad, es la propia carne la que a través de su función expresiva -en tanto que fusión de perspectivas- delata lo que pasa en el dentro que es la intimidad y sobre la que en, última instancia, se construye la relación o trato social, cierto grado de mutualidad. Y es que las intimidades, en tanto que no materiales, no sólo están presentes como los cuerpos sino compresentes; pueden, de algún modo, fundirse y compartir la perspectiva: 
El cuerpo del otro, quieto o en movimiento, es un abundantísimo semáforo que nos envía las más variadas señales o indicios o barruntos de lo que pasa en el dentro que es el otro hombre. Ese dentro, es intimidad, pero es compresente [...]. La fisonomía de ese cuerpo, su mímica y su pantomímica, gestos y palabras no patentizan pero sí manifiestan que hay allí una intimidad similar a la mía. El cuerpo es un fertilísimo "campo expresivo» o de «expresividad». (ORTEGA Y GASSET, 1981c, p. 98-99).

Si ya en la Meditaciones del Quijote había señalado Ortega que la vida "es el texto eterno" (ORTEGA; GASSET, 1976, p. 87), en lo que Gutiérrez-Pozo (2012, p. 82) ha identificado como la base hermenéutica del raciovitalismo, aquí el cuerpo asciende al primer plano de lo vital, de lo biográfico, al convertirse en un verdadero logos, en un nudo de señales cuyo juego narrativo (e interpretativo) entre la opacidad y la transparencia es la antesala de la vida social.

\section{Fenomenología de la APARICIÓN DEL OTRO}

Aunque la vida auténtica del hombre está su soledad radical y en esta encuentra su última verdad, aquel no aparece en la soledad sino en la socialidad, con el otro como reciprocante necesario. Es decir, en un mundo de acciones y no de meras conductas según la diferenciación que Ortega hace en las primeras páginas de El hombre y la gente y con la que entra en disputa con Weber y Schütz, según ha señalado Benítez (1983); diferenciación según la cual "acción no es cualquier andar a golpes con las cosas en torno, o con los otros hombres: eso es infrahumano, eso es alteración. La acción es actuar sobre el contorno de las cosas materiales o de los otros hombres conforme a un plan preconcebido" (ORTEGA Y GASSET, 1981c, p. 36).

Desde esta perspectiva, no se puede decir que la aparición del otro sea un hecho sobrevenido a nuestra realidad; el otro es un hecho que se constituye como la espalda de nuestra vida porque al sorprendernos -a nosotros mismos- por primera vez viviendo, nos encontramos ya no sólo con los otros sino habituados a ellos o, lo que es lo mismo, "antes de que cada uno de nosotros cayese en la cuenta de sí mismo, había tenido ya la experiencia básica de que hay los que no son "yo», los otros" (ORTEGA Y GASSET, 1981c, p. 112); esto hace de cada uno de nosotros un ser necesariamente altruista que, en la relación con los objetos del mundo (mío) -comunes a mí y al otro sólo con ligeras variantes de perspectiva-, puede advertir 
la idea de un presunto mundo común a todos, lo que llamamos «mundo objetivo». Y es que los impenetrables cuerpos de forma humana, los otros cuasi-yos con sus vidas - realidades radicales de ellos- y sus mundos propios, si bien no son inmanentes a mi vida y a mi mundo sino transcendentes -más allá de mi propia vida-, son patentes; su presencia directa o compresencia "me emboca y enfronta con algo transcendente a mi vida y, por tanto, que está en ésta sin propiamente estar" (ORTEGA Y GASSET, 1981c, p. 102) pero, de cualquier manera $-\mathrm{y}$ casi en clave cartesiana que el propio Ortega denomina: " "Cartesianismo de la vida" y no de la cogitatio" (ORTEGA Y GASSET, 1981b, p. 58)-, su realidad me es patente no radicalmente, no indubitablemente, sino de forma presunta, a diferencia de mi propia vida cuya soledad es la realidad radical.

La aparición del otro, bajo presunción de que es un yo como el mío, con una vida como la mía y, por tanto, no mía sino suya y con un mundo propio donde él vive radicalmente, constituye el primer ejemplo en el que Ortega encuentra realidades que no son radicales, sino meras presunciones que, en rigor, son ideas o interpretaciones de la realidad. No obstante, el otro, en cuanto que objeto de mi mundo, se muestra impenetrable físicamente, pero patente desde mi perspectiva radical "el cuerpo del otro me es radical e incuestionable realidad" (ORTEGA Y GASSET, 1981c, p. 10); ahora bien, decir que en ese cuerpo "habita un cuasi-yo, una cuasi-vida humana, es ya una interpretación mía -señala Ortega-. La realidad del otro hombre, de esa otra "vida humana» es, pues, de segundo grado en comparación con la realidad primaria que es mi vida, que es mi yo, que es mi mundo" (ORTEGA Y GASSET, 1981c, p. 10).

Este cuerpo del otro, ingresado en el horizonte de cada cual -antes incluso de darnos cuenta de nuestra propia realidad radical- nos es presente sólo mediante un cuerpo que es carne y que, sobre el resto de las señales, tiene el enigmático don de señalarnos -apunta Ortega- un intus o intimidad: su faz, su perfil, su talle entero, su ir y venir, sus movimientos, su gesticulación, la mirada son ya expresión de ese alguien que intuimos o presumimos y sobre el que se produce la genuina relación social.

El atributo característico del otro es que responde (o puede responder) a mi acción, lo cual me obliga a contar a mí con su reacción, de manera que constituye una "realidad nueva y sui generis, inconfundible con cualquier otra, [...] una acción en que va inserta, interpenetrada e involucrada la del otro y que es, por lo tanto, inter-acción” (ORTEGA Y GASSET, 1981c, p. 146). En 
definitiva, que el otro sea reciprocante de mí ab initio constituye el fundamento de que sea, aunque no en esencia, un ser social.

Pero aún se puede ir más allá en el análisis de la relación social. En el encuentro con el otro, con el otro hombre, uno descubre que este es fundamentalmente un ser extrańo a mí, el esencial extranjero cuyo mundo, coincidente en alguna parte con el mío propio, descubro en mi trato con él. Lo que del otro me es extraño y extranjero se proyecta sobre el mundo común a ambos; el mundo objetivo, el de todos los hombres en cuanto forman sociedad y que, por no ser auténticamente mi mundo, me es inhóspito. El mundo objetivo, común a todos, pero de nadie, es el mundo de la convivencia y de la convencionalidad de tal modo que -según Ortega- "mientras convivimos en el Mundo vivimos en el extranjero" (ORTEGA Y GASSET, 1981c, p. 148): mientras convivimos nos hallamos alejados de la soledad radical y, en ese sentido, en mayor o menor medida, según nuestra docilidad a lo que los otros hombres hacen y dicen, nadie puede sustraerse -sin dejar de ser hombre- a vivir una pseudo-realidad.

Pero, ¿cómo se configura la primera relación con el otro, la primaria forma de socialidad por la que -según lo expuesto- se produce esa pseudovida, vida social o vida humanizada? En la realidad nosotros, nostridad o, simplemente, trato -apunta Ortega-. Cuando dicho trato se hace frecuente el otro se va perfilando, determinando y aproximando hasta convertirse en tú; es decir, en individuo inconfundible, incanjeable, cuyo grado extremo de proximidad es lo que llamamos intimidad; un grado del que se podría decir -interpretando la letra de Ortega- que el cuerpo, la carne, queda desvanecida.

Y puesto que la conversión del otro en tú-señala Ortega- no me pasa sólo con uno, sino con bastantes hombres, me encuentro con que el Mundo humano me aparece como un horizonte de hombres cuyo círculo inmediato está lleno de tús únicos; más allá se hallan zonas circulares ocupadas por hombres de quienes sé menos y así sucesivamente hasta que en el horizonte de mi contorno humano se hallan "los individuos para mí cualesquiera, intercanjeables” (ORTEGA Y GASSET, 1981c, p. 152) y, por lo tanto, de más lejana humanidad: aquellos a los que veo como semejantes (corporalmente) y con quienes tengo una socialidad sólo potencial. Se trata de que en nuestro contorno se hallan repartidos los hombres según una perspectiva de humanidad; es decir, más o menos individualizados, más o menos íntimos hasta llegar al punto cero de intimidad o situación en la que del otro sólo sé que es mi semejante por su aspecto corporal: "Del puro otro, en cero de intimidad, 
no tengo más intuición directa que lo que de su presencia y compresencia momentánea me viene, no tengo más que la visión de su cuerpo, de sus gestos, de sus movimientos, en todo lo cual creo ver un hombre, pero nada más" (ORTEGA Y GASSET, 1981c, p. 156-157); en todo caso, un enorme hueco de ser humano al que nada de lo humano le es ajeno y que, por eso mismo -según la visión dramática y agonística de la vida orteguiana en la que el prójimo es, antes que nada, una amenaza-, obliga a comenzar el trato con él de forma cautelosa.

A este respecto, cabe recordar que lo que incita a Ortega a reflexionar sobre la relación social es la búsqueda del objeto y el sentido de la sociología así como su descripción; una tarea no resuelta, según su parecer, en ninguno de los tratados de la materia escritos desde Comte. En esta búsqueda, realizada desde la presentación de la soledad como realidad radical del hombre, constituye un elemento de primera magnitud el concepto de disociedad como aspecto contradictorio y contrafactorio que provoca el encuentro con el otro: la posibilidad de que el otro actúe de manera hostil, es decir, contra mí. Una eventualidad de la convivencia sin la cual no es posible comprender la sociedad ni tampoco hacer sociología.

En este orden de cosas, podríamos denominar superabundancia corporal del otro, cuando de él todo nos es hueco de modo que la exterioridad de su cuerpo, su primera impresión nos ofrece infinitas posibilidades de ser. Pero estas posibilidades sufren una reducción a solo unas pocas concentradas -las que determinan un $t u$ - lo cual se produce en la medida en que voy entrando en contacto con su cuerpo según un proceso en el que, curiosamente, del otro se va perdiendo el cuerpo. Y es así porque, en efecto, en la visión continua de su fisonomía, de sus gestos y de sus movimientos, de todos sus actos externos, en los que leemos buena parte de su intimidad y entrevemos su vida, sucede como si en el contacto con su cuerpo, este se desdibujara ante la fuerza que adquiere su intracuerpo; donde intracuerpo, como vimos más arriba, no es cuerpo, sino que es la intimidad, es el tú con el que verdaderamente establezco el trato de pariente, de amigo o de compańero a pesar de que siempre quedan recovecos de su ser en los que no logro penetrar: resquicio de la libertad de ser. Este tú, metafóricamente hablando casi incorpóreo, es frecuentemente negación de mi ser en tanto que de él emergen deseos coincidentes con los míos, que chocan con los míos, y por los que tenemos que luchar. De esta particular lucha, en la que descubrimos los peligros de la convivencia con el otro, emergen frecuentes negaciones de mi ser; pero no negaciones pasivas sino activas que se disparan 
hacia mí haciendo que yo "descubra mis límites, mis fronteras con tu mundo y contigo” (ORTEGA Y GASSET, 1981c, p. 166).

Resulta sobremanera interesante, por la negación activa del yo que supone el topetazo con el otro, no solo la literalidad sino también el tono que emplea Ortega. A diferencia de otros pasajes y en obras anteriores, en que la soledad radical adoptaba un tono grave y se podría decir que doliente: "El dolor ajeno no es realidad radical [...] mi humana vida, que me pone en relación directa con cuanto me rodea -minerales, vegetales, animales, los otros hombres-, es, por esencia, soledad. Mi dolor de muelas -dije- sólo a mí me puede doler" (ORTEGA Y GASSET, 1981c, p. 47, 65), en esta ocasión en que las resistencias al yo corpóreo se resuelven en la socialidad, la negación de mi mismidad adopta un pulso proyectivo; adopta un pulso casi liberador que Ortega compara con lo que le sucede al nińo cuando empieza a percibir la realidad más allá de su cuerpo. Porque antes de que apareciera el otro en mi soledad radical -dice- y al igual que en mi primerísima infancia creía que todo el mundo era yo o, lo que es igual, mío, mi mismo cuerpo me parecía sin límites:

Me parecía llegar hasta el horizonte. Fue menester que me trompicase con los muebles de casa -mesas y cómodas- y me hiciese chichones para ir descubriendo dónde mi cuerpo terminaba y comenzaban las otras cosas. Mesas y cómodas son, desde que las hay, los primeros mudos pedagogos que enseńan al hombre las fronteras, los límites de su ser -por lo pronto, de su ser corporal (ORTEGA Y GASSET, 1981c, p. 166-167).

\section{Cuando el otro es una Mujer}

Constituye, para Ortega y Gasset, una especialísima relación social la que se establece con el otro, desde la masculinidad dominante, cuanto el otro es ella. Cada paso que da el hombre, hace entrar en su horizonte nuevas cosas que van configurando el mundo, su mundo, desde el centro que es el aqui y en el que el cuerpo está; así aparecía el otro del que no nos es presente más que su cuerpo, carne que -como había señalado ya en Sobre la expresión fenómeno cósmico-se nos presenta como la exteriorización de algo esencialmente interno (el intus, intimidad, a veces intra-cuerpo y también alma) que en el caso de la mujer registra connotaciones particulares.

La relación que de suyo establece el hombre cuando aparece en escena el otro se fragua sobre la capacidad intracorporal de responder, de reciprocar, derivada de cierta analogía especulativa, abstracta, que el yo podía establecer 
entre su ego y su alter ego. Aunque de por sí el sentido de la expresión alter ego es contradictoria e irreal porque ego sólo es en mí -dice Ortega-, permite no obstante comprender los componentes comunes entre el otro y yo en una especie de transposición que abre el camino a la relación o trato social. Sin embargo, en el caso de la mujer -precisa Ortega- la posibilidad de tal transposición queda anulada por la esencial heterogeneidad entre mi ego, que es esencialmente masculino, y el suyo, cuya respuesta es "sin más, femenina y yo la advierto como tal” (ORTEGA Y GASSET, 1981c, p. 133).

La casuística del cuerpo femenino, en cuanto tal, ya la había desarrollado Ortega, años atrás, en La percepción del prójimo -integrado en Ideas y creenciasdonde venía a afirmar, acaso influido por Scheler (ORRINGER,1999, p. 35), que la mujer presenta un grado de penetración entre el cuerpo y el espíritu mucho más elevado que en el varón en quien a menudo - dice- actúan cada uno por su lado, como irreconciliables enemigos (ORTEGA Y GASSET, 1986, p. 135). De tal modo sería la contextura fisiológica de la mujer que para ella su cuerpo existiría más que para el hombre el suyo, hallándose además el cuerpo femenino transido y como saturado de espíritu (ORTEGA Y GASSET, 1986, p. 136-137).

Aunque las formas del cuerpo femenino se diferencian bastante de las del cuerpo masculino, no sería causa suficiente -señala ya en El hombre y la gente- para descubrir en él a la mujer, la cual a veces induce a error. Serían, por el contrario, aquéllas partes que menos distinguen a uno y a otra las que, en su modo de com-presencia, manifiestan su feminidad. Se puede deducir de ello, y de alguna manera lo apunta el propio Ortega, que paradójicamente en el caso de la mujer no es su cuerpo el que revela un «alma femenina», sino el "alma femenina» la que revela su cuerpo; es "un extraño modo de ser humano profundamente distinto del masculino" (ORTEGA Y GASSET, 1981c, p. 135) el que denota la formas corporales peculiarmente femeninas, el que "rezuma sobre su cuerpo y lo feminiza" (ORTEGA Y GASSET, 1981c, p. 136).

Los caracteres primarios que ve Ortega en la presencia de la mujer y que son constituyentes de una corporalidad femeninamente impregnada no dejan de constituir una controvertida argumentación -evocadora en casi todos sus extremos de la somatología medieval- que podría dar lugar a no poco vehementes discusiones sexistas (con sobradísima razón) pero que, no obstante, cierran el círculo perspectivista-egotista iniciado con la heterogénea presencia de un otro que, eventualmente, es otra. Estos caracteres son, en primer lugar, que su íntima humanidad es esencialmente confusa y constitutivamente secreta, 
supuesta virtud por ser esto -apunta Ortega- la delicia del varón. En segundo lugar, que la intimidad que en el cuerpo femenino descubren (los varones) se nos presenta como "una forma de humanidad inferior a la varonil", también razón de la "sin par delicia que es para el hombre masculino, la mujer" y motivo de inspiración que hace de ella no "un producto de la naturaleza, sino una invención de la historia como lo es el arte" (ORTEGA Y GASSET, 1981c, p. 137-140); un producto al que -señala- habría que considerar como un género literario. Finalmente, la peculiar relación que la mujer establece con su cuerpo; esta como consecuencia de la confusión y debilidad hace que sus sensaciones orgánicas sean más vivas y más intensas, hace que se halle "más fundida con su cuerpo que el hombre; es decir, su alma es más corporal, pero, viceversa, su cuerpo convive más constante y estrechamente con su espíritu" (ORTEGA Y GASSET, 1981c, p. 142).

Quizás como descargo de lo que a la luz de las palabras no se puede descargar, concluye Ortega sus disquisiciones fenomenológicas en torno a la mujer y su presencia corporal en la sociedad, apuntando cómo la (supuesta) propensión histórica de la mujer al ornato de su cuerpo constituye el síntoma de la responsabilidad femenina en la creación de la "egregia cultura del cuerpo, que históricamente empezó por el adorno, siguió por el aseo y ha concluido por la cortesía, genial invento femenino que es, en resolución, la fina cultura del gesto." El resultado de la atención constante de la mujer a su cuerpo señala- hace que este nos aparezca como impregnado de alma; en ese sentido, la atracción erótica que produce en el varón no es suscitada por el cuerpo femenino en cuanto cuerpo sino en tanto que "el cuerpo de ella es un alma" (ORTEGA Y GASSET, 1981c, p. 143).

VICENTE-PEDRAZ, M; BROZAS-POLO, M. P. The body as a basis of sociality in Ortega y Gasset. Trans/form/ação, Marília, v. 41, n. 3, p. 169-188, Jul./Set., 2018.

\footnotetext{
Abstract: This article is an approach to the notion of the body in Spanish philosopher Jose Ortega y Gasset (1883-1955), especially with regard to its relation to his phenomenological inquiry into sociality. From the analysis of Ortega's most representative texts on sociology and anthropology, it is shown that the body is not an isolated or sporadic element in his writing, but rather a mediating element that is most representative of his thought.
}

Keywords: Ortega y Gasset. Body. Expression. Society. Sociality. 


\section{Referencias}

BASSANI, J. J.; VAZ, A. F. Dialéctica do progreso e do domínio da naturaleza: técnica en Theodor W. Adorno e José Ortega y Gasset. Pro-posições, Campinas, v. 25, n. 3, p. 211 227, 2014. Disponible en: http://www.scielo.br/pdf/pp/v25n3/v25n3a11.pdf. Acceso en: 15 jun 2016.

BENÍTEZ, A. El concepto de acción social según Ortega. Teorema, Revista Internacional de Filosofia, Oviedo, v. 13 n. 3-4, p. 505-522, 1983. Disponible en: https://dialnet. unirioja.es/servlet/articulo?codigo=2043910. Acceso en: 15 jun 2016.

CARVALHO, J. M. Ortega y Gasset, a vida como realidade metafísica. Trans/Form/Ação, Marília, v. 38, n. 1, p. 167-186, 2015. Disponible en: http://www2.marilia.unesp.br/ revistas/index.php/transformacao/article/view/4880/3504. Acceso en: 15 jun 2016.

CEREZO, P. La voluntad de aventura: aproximamiento crítico al pensamiento de Ortega. Barcelona: Ariel, 1984.

GAOS, J. Ortega y Heidegger. La palabra y el hombre, Veracruz, v. 5, n. 19, p. 403-439, 1961. Disponible en: http://cdigital.uv.mx/bitstream/123456789/3029/1/1961019P403. pdf. Acceso en: 15 jun 2016.

GUTIÉRREZ-POZO, A. La vida como principio hermenéutico radical en la Filosofía de Ortega y Gasset. Trans/Form/Ação, Marília, v. 35, n. 3, p. 81-96, 2012. Disponible en: http://www2.marilia.unesp.br/revistas/index.php/transformacao/article/view/2627/2060. Acceso en: 15 jan 2015.

HARO, A. Antropología de los usos sociales como constitutivos de la "gente". Un estudio desde Ortega. Gazeta de Antropología, v. 26, n. 1, art. 2, 2010. Disponible en: http:// www.ugr.es/-pwlac/G26_02Alejandro_DeHaro_Honrubia.html. Acceso en: 15 jan 2016.

KOPRINAROV, L. Cuerpo comunicativo. José Ortega y Gasset sobre el lenguaje como gesticulación. Themata: Revista de Filosofía, Sevilla, n. 46, p. 529-535, 2012. Disponible en: http://institucional.us.es/revistas/themata/46/art_49.pdf. Acceso en: 15 jun 2016.

LAÍN ENTRALGO, P. El cuerpo humano: teoría actual. Madrid: Espasa, 2012.

MALISHEV, M.l; HERRERA J. José Ortega y Gasset: la metafísica existencial de la vida. Eidos. Revista de Filosofía de la Universidad del Norte, México, n. 12, p. 214-235, 2010. Disponible en: http://rcientificas.uninorte.edu.co/index.php/eidos/article/view/146/318. Acceso en: 15 jan 2015.

MARÍAS, J. Antropología metafísica. Madrid: Alianza, 1983.

MERMALL, T. Ortega y Bergson: un paralelismo sociológico. Revista Canadiense de Estudios Hispánicos, Montreal, v. 13, n. 1, 1988.

ORRINGER, N. La corporalidad en Ortega y Gasset. Pamplona: Servicio de Publicaciones de la Universidad de Navarra, 1999.

ORTEGA Y GASSET, J. El espectador VII y VIII. Madrid: Espasa-Calpe, 1966. 
- Meditaciones del Quijote: ideas sobre la novela. Madrid: Espasa-Calpe, 1976.

—. El tema de nuestro tiempo. Madrid: Espasa-Calpe, 1980.

- ¿Qué es filosofía? Madrid: Espasa-Calpe, 1981a.

- Historia como sistema. Madrid: Alianza, 1981b.

—. El hombre y la gente. Madrid: Alianza, 1981c.

—. Meditación de la técnica y otros ensayos sobre ciencia y filosofia. Madrid: Alianza, 1982.

—. Ideas y creencias. Madrid: Alianza, 1986.

—. Vitalidad, alma, espíritu (El espectador V). In: Obras Completas II. Madrid: Alianza, 1987.

OSÉS, J. M. La sociología de Ortega y Gasset. Barcelona: Anthropos, 1989.

SAN MARTÍN, J. La fenomenología de Ortega. Madrid: Biblioteca Nueva, 2012.

SANMARTÍN, R. En torno a Ortega y la gente: Ortega y la antropología cultural. Reis, Madrid, n. 82, p. 73-96, 1998. Disponible en: http://www.reis.cis.es/REIS/PDF/ REIS_082_05.pdf. Acceso en: 15 jun 2016.

Recebido: 2016-04-04

Aceito: 2017-09-08 
VICENTE-PEDRAZ, M.; BROZAS-POLO, M. P. 